\title{
Analytical Evaluation of the Human Papillomavirus HPV DNA Array E1-Based Genotyping Assay
}

\author{
Aleksandra Pesic ${ }^{\mathrm{a}}$ Amrei Krings $^{\mathrm{a}}$ Carola Schreckenberger $^{\mathrm{a}}$ \\ Matthias Hempel $^{b}$ Rosemarie Preyer ${ }^{b}$ Andreas M. Kaufmann ${ }^{a}$ \\ aGynaecology Clinic, Charité Universitätsmedizin, Corporate Member of Freie Universität Berlin, Humboldt- \\ Universität Berlin and Berlin Institute of Health, Berlin, Germany; ${ }^{b}$ AID/GenID Diagnostika, Strassberg, Germany
}

\section{Keywords \\ Cervical cancer $\cdot$ GP5 $+/ 6+\cdot$ HPV detection $\cdot$ Human \\ papillomavirus $\cdot$ Luminex $\cdot$ Multiplex $\cdot$ Validation}

\begin{abstract}
Background: Cervical cancer is caused by a persistent infection of human papillomavirus (HPV). Therefore, tests which detect the carcinogenic virus can be used for cervical cancer screening. Objective: This is the first evaluation of the HPV DNA Array (AID Diagnostika, Strassberg, Germany), an E1-based genotyping polymerase chain reaction (PCR) test for identification of 29 HPV types $(6,11,16,18,26,31$, $33,35,39,40,42,44,45,51,52,53,54,56,58,59,66,67,68$, $69,70,73,82,85$, and 97). Methods: Analytical performance of the assay was assessed with cervical cancer cell lines with known HPV status, and preselected clinical cervical scrapings genotyped by multiplexed genotyping (MPG) with a Luminex readout (validated in-house assay). Intra- and inter-laboratory reproducibility experiments were performed to ensure the reliability of the assay. Results: HPV DNA Array identified the intrinsic HPV genotype in all cervical cancer cell lines and demonstrated a high sensitivity for HPV16 probe ( 1 cell per PCR reaction), as well as HPV18 and 45
\end{abstract}

probes (100 cells per PCR reaction). When compared with MPG, HPV DNA Array showed a good agreement of 92.2\% for HPV detection irrespective of type $(\kappa=0.601)$, and demonstrated high agreement for HPV16 $(80.7 \%, \mathrm{~K}=0.836)$ and HPV18 $(86.7 \%, \mathrm{~K}=0.925)$. Furthermore, high intra-/interlaboratory reproducibility was observed (90.9-100\%). Conclusion: HPV DNA Array showed high sensitivity for correct HPV genotype detection in experimental and clinical samples with a good correlation to the reference test. Since HPV DNA Array is based on a simple multiplexed PCR followed by reverse hybridization in a 96-well format and automated visual readout by AID ELISpot reader, it is capable of high throughput in a time-effective manner. HPV DNA Array could be considered for extended HPV genotyping of cervical smears.

(c) 2019 The Author(s) Published by S. Karger AG, Basel

\section{Introduction}

Human papillomavirus (HPV) infection is one of the most common sexually transmitted infections among sexually active women [1]. There are more than $40 \mathrm{HPV}$

\begin{tabular}{ll}
\hline KARGER & $\begin{array}{l}\text { C } 2019 \text { The Author(s) } \\
\text { Published by S. Karger AG, Basel }\end{array}$ \\
E-Mail karger@karger.com & This article is licensed under the Creative Commons Attribution- \\
www.karger.com/int & NonCommercial-NoDerivatives 4.0 International License (CC BY- \\
& NC-ND) (http://www.karger.com/Services/OpenAccessLicense). \\
Usage and distribution for commercial purposes as well as any dis- \\
tribution of modified material requires written permission.
\end{tabular}

Dr. Andreas M. Kaufmann

Gynäkologische Tumorimmunologie R. 4503, Gynäkologie mit Hochschulambulanz Charite-Universitätsmedizin Berlin, Campus Benjamin Franklin

Hindenburgdamm 30, DE-12200 Berlin (Germany)

E-Mail andreas.kaufmann@ charite.de 
types identified to have high tropism for genital mucosal epithelia [2]. HPV types causing genital warts and benign lesions are labeled low-risk (LR) types, among which HPV6 and 11 are most commonly found [3]. HPV types associated with cervical cancer are grouped as high-risk (HR) HPV types [4]. The most clinically significant HRHPVs are HPV16, 18, 31, 33, 35, 39, 45, 51, 52, 56, 58, 59, 66 , and 68 . Cumulatively, they have been found in $94.5 \%$ of all squamous cell carcinomas of the cervix worldwide [5].

Historically, cytology is the method most often used to screen for cervical intraepithelial lesions [6]. However, its limitations, for example moderate sensitivity for detection of disease (44-78\%) [7], the causality between cervical cancer and HPV [5], and advancement of detection methods have led to a shift to and approval of HPV testing as the primary screening method.

There is indication that full HPV genotyping may be superior to HPV-positive/negative testing [8-10]. Genotyping for certain HPV types could provide valuable clinical information, because not all HPV types bear the same risk for cancer development, for example HPV16+ lesions are significantly less likely to regress than lesions positive for other HR-HPV types [11]. Any information on type shifting and persistence after treatment may have a clinical impact [12]. An additional advantage of genotyping may be the identification of multiple HPV infections. Women infected with multiple types of HPV have an increased risk of developing cervical cancer [13]. Identification of the specific genotypes is also important to evaluate their frequency in epidemiological studies.

The purpose of this study was to evaluate the technical performance of the HPV DNA Array, a full genotyping assay developed by AID Diagnostika (Strassberg, Germany), which is CE-marked for in vitro diagnostic in the European Union. The HPV DNA Array is an E1-based DNA multiplex polymerase chain reaction (PCR) assay, with ability for full HPV genotyping of 29 HPV types: 18 HR-HPV types $(16,18,26,31,33,35,39,45,51,52,53,56$, $58,59,66,68,73,82)$ and 11 LR-HPV types $(6,11,40,42$, $44,54,67,69,70,85,97)$, as well as 3 internal controls. HPV is detected by multiplex PCR and subsequent reverse dot blot hybridization with type-specific oligonucleotide probes. These probes are spotted into one single well of a 96-well microtiter plate. Plates are evaluated and results computed by an ELISPOT reader and proprietary AiDot software (AID Diagnostika).

The performance of the HPV DNA Array and intra-/ inter-reproducibility were determined by using cell lines and archived material previously genotyped with the gold standard assay BS GP5+/6+ multiplexed genotyping (MPG) with a Luminex-based readout $[14,15]$.

\section{Materials and Methods}

Sample Set and Preparation

To assess the analytical performance of HPV DNA Array, 2 sets of samples were used: (i) cultured cell lines with known HPV status, and (ii) preselected clinical cervical scrapings with known HPV status, genotyped by MPG.

Cell Lines

Seven cervical cancer cell lines were obtained from LGC Standards GmbH (Wesel, Germany) and cultured according to American type culture collection instructions, that is HeLa (HPV18+, ATCC $^{\circledR}$ CCL-2 $^{\text {TM }}$ ), CaSki (HPV16+, ATCC $^{\circledR}$ CRL-1550 ${ }^{\mathrm{TM}}$ ), SiHa (HPV16+, ATCC ${ }^{\circledR}$ HTB-35 ${ }^{\mathrm{TM}}$ ), CERV (HPV45+, ATCC ${ }^{\circledR}$ HTB$34^{\mathrm{TM}}$ ), MS751 (HPV45+, ATCC ${ }^{\circledR}$ HTB-34 $^{\mathrm{TM}}$ ), ME180 (HPV68+,

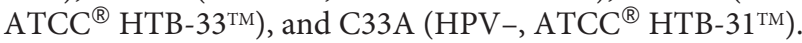

\section{Clinical Cervical Scrapings}

From the laboratory sample repository, $244 \mathrm{HPV}$-positive DNA samples were selected: 157 samples with single HR-HPV infection, 27 with single LR-HPV infection, and 60 samples with multiple HPV infections. At least 1 sample to represent any type included in the HPV DNA Array spectrum was selected, however, HPV40-, 44-, 67-, 69-, 85-, and 97-positive samples were not available. In addition, as controls, $28 \mathrm{HPV}$-negative samples were included. Samples were obtained from women undergoing colposcopic examination at the outpatient referral Gynecology Clinic, Charité Universitätsmedizin Berlin, Germany. Patients consented to the use of residual material for research (IRB No. EA1/168/13). Cervical scrapings were taken by cytobrush rinsed in ThinPrep (Hologic, Bedford, MA, USA), and stored at $+4^{\circ} \mathrm{C}$ until analysis. DNA was extracted by QIAamp DNA Mini Kit from $2 \mathrm{~mL}$ of a $20-\mathrm{mL}$ total sample volume. Nucleic acid was eluted to a final volume of $160 \mu \mathrm{L}$. HPV genotyping was performed with MPG using $5 \mu \mathrm{L}$ of DNA extract per PCR reaction.

\section{$M P G$ with Luminex-Based Hybridization following BS-GP} $5+/ 6+P C R$

BS GP5+/6+ MPG assay with Luminex-based readout is a wellestablished assay proficient for HPV genotyping with high analytical sensitivity [16]. MPG is an L1-based PCR DNA test which is used routinely in our laboratory for HPV detection of the following HPV types: $6,11,16,18,26,31,33,35,39,42,43,45,51,52$, $53,54,56,57,58,59,66,68,70,72,73,82$, and 90 . Additionally, the assay measures the cellular beta-globin of each sample, as a control for the adequate DNA amount. The MPG genotyping was carried out generally as described by Schmitt et al. [14, 15]; however, in our laboratory a final PCR volume of $25 \mu \mathrm{L}$ was used. The assay's quality was controlled by participation in proficiency testing (Instant e.V. and Equalis) and compared to the commercially available version Optiplex (Diamex, Heidelberg, Germany).

\section{HPV DNA Array}

The HPV DNA Array (AID Diagnostika) included 18 HR genotypes $(16,18,26,31,33,35,39,45,51,52,53,56,58,59,66,68$, 

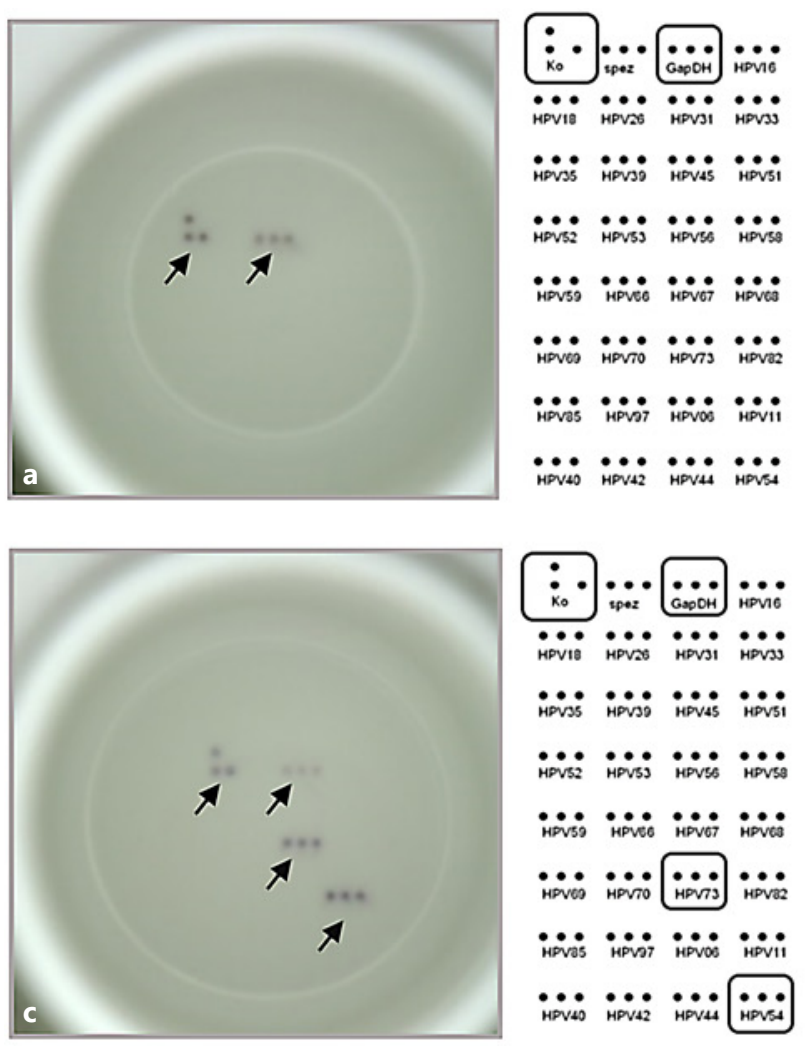

Fig. 1. HPV DNA Array probe organization. Close-up pictures of 4 wells in a 96-well plate with spotted probes for detection of 29 HPV types and 3 controls, next to a probe-spotting pattern with highlighted positions. Arrows point to controls and to an HPV-

73, 82) and 11 LR HPV types $(6,11,40,42,44,54,67,69,70,85$, 97). The assay detects HPV by amplifying E1-gene sequences of approximately 180 base pairs in length by multiplex PCR with specific biotin-labeled primers. The duration of the PCR program is $55 \mathrm{~min}: 1 \mathrm{cycle}\left(3 \mathrm{~min}\right.$ at $\left.95^{\circ} \mathrm{C}\right), 10$ cycles $\left(10 \mathrm{~s}\right.$ at $96^{\circ} \mathrm{C}$ and $20 \mathrm{~s}$ at $\left.60^{\circ} \mathrm{C}\right), 26$ cycles $\left(10 \mathrm{~s}\right.$ at $95^{\circ} \mathrm{C}, 15 \mathrm{~s}$ at $55^{\circ} \mathrm{C}$, and $15 \mathrm{~s}$ at $\left.72^{\circ} \mathrm{C}\right)$, and 1 cycle $\left(3 \mathrm{~min}\right.$ at $\left.72^{\circ} \mathrm{C}\right)$. Per PCR reaction, $4.8 \mu \mathrm{L}$ of DNA and 20.2 $\mu \mathrm{L}$ of Master Mix, in a total volume of $25 \mu \mathrm{L}$, were used. For each PCR run negative and positive controls $(\mathrm{GapDH})$ were included to control the PCR performance. The amplified gene fragments were detected by a hybridization reaction with sequence-specific oligonucleotide probes, specific for each HPV type. All probes are spotted as triplets and immobilized at the bottom of each well of a 96-well microtiter plate (Fig. 1). Twenty-five microliters of PCR amplicons were denatured by using $25 \mu \mathrm{L}$ of denaturation reagent to allow binding to immobilized oligonucleotide probes. Ten microliters of this mix were placed into a well for hybridization to the spotted HPV genotype-specific probes. A stringent washing procedure ensured binding only when there was $100 \%$ sequence homology. Streptavidin-coupled alkaline phosphatase was used to detect biotin-labeled amplified DNA hybrids by color reaction with BCIP/NBT. Spots were evaluated by ELISpot reader and reading software AiDot (AID Diagnostika). Spots were considered as
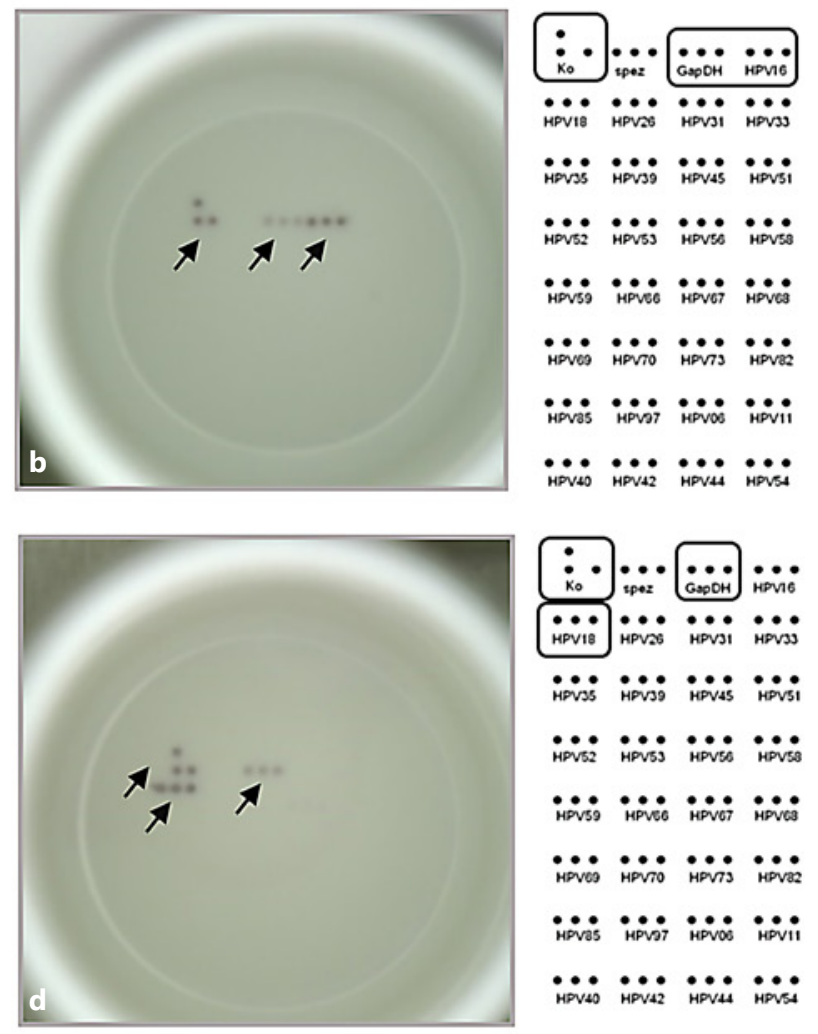

specific signal. a Example of an HPV-negative well (conjugate and GapDH controls appear positive). b An HPV16-positive well with signals at HPV16 and control positions. c HPV54- and 73-positive wells with controls. d HPV18-positive well with controls.

positive when the color strength was stronger than $10 \%$ of the strength of the conjugate control probe (Fig. 2). In addition, in each well 3 internal controls were spotted: GapDH control for verification of adequate DNA content, a conjugate control for correct test execution, and a specificity control to detect any potential unspecific binding. Data obtained by ELISpot reader and reading software AiDot can be exported (e.g., Microsoft Word) and pictures of each well stored.

\section{HPV DNA Array Sensitivity Tested with Cell Lines}

To test the stability of cells and suitability of 2 different storage transport media (SM), with fixating and non-fixating SM, cells were suspended in phosphate-buffered saline (PBS) and in PreservCyte (Hologic Inc., Marlborough, MA, USA). DNA was extracted from $1 \mathrm{~mL}\left(10^{6}\right.$ cells $/ \mathrm{mL}$ ) by QIAamp DNA Mini Kit (Qiagen, Hilden, Germany) following the manufacturer's instructions. Nucleic acid was eluted in a final volume of $160 \mu \mathrm{L}$. All samples were tested under identical conditions, and PCR amplification was performed and tested in duplicates. HPV genotyping was performed with MPG using $4.8 \mu \mathrm{L}$ of DNA extract per PCR reaction.

To determine the sensitivity of the HPV DNA Array for HPV16, 18,45 , and GapDH probes, a titration of SiHa, HeLa, and MS751 cell lines was performed. Samples of 2 different passages of each 


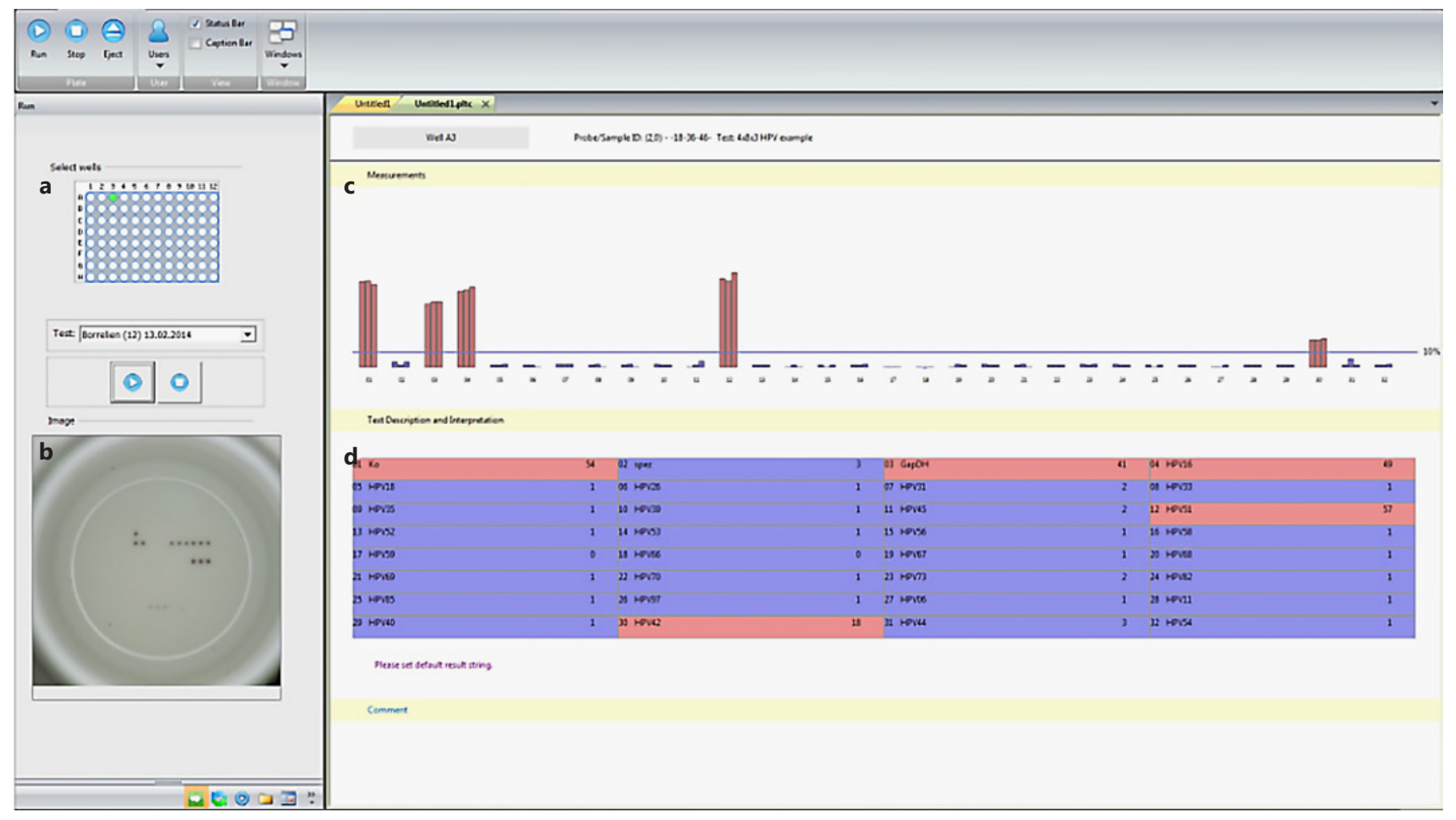

Fig. 2. AiDot software interface for evaluation of the HPV DNA Array plate. Icons and menus are present at the top. a The location of the currently evaluated well on the plate is marked in green. $\mathbf{b}$ Image of the respective well. c Strength of coloring of the 3 corresponding probe spots for each HPV probe (blue line: cut-off for positivity preset at $10 \%$ of coloring strength of the conjugate probe

cell line were suspended in PBS with a concentration of $10^{6}$ cells/ $\mathrm{mL}$ and stored at $-20^{\circ} \mathrm{C}$ until DNA extraction with a QIAamp DNA Mini Kit. Nucleic acid was eluted to a final volume of $160 \mu \mathrm{L}$. Dilution series of the isolated DNA were made in sterile water to obtain concentrations from $10^{4}$ cells/PCR reaction to $10^{-2}$ cells/ $\mathrm{PCR}$ reaction for each cell line and passage. Dilutions were tested under same conditions with HPV DNA Array.

\section{Intra- and Inter-Laboratory Reproducibility}

Assay reliability was tested by intra- and inter-laboratory reproducibility experiments. From the laboratory sample repository, 22 cervical samples were selected: 3 HPV negative and 19 HPV positive, 8 with a single and 11 with multiple HPV infections. Within the intra-laboratory reproducibility testing, an intra- and inter-assay comparison was performed. For the intra-assay experiment, the same PCR product of the sample set was tested as quadruplicates on the same assay plate in one run by 1 performer using the same assay lot. In the inter-assay setting, the sample set was tested independently by 3 performers using different assay lots. For the inter-laboratory reproducibility testing, DNA aliquots of the sample set were sent to 2 external laboratories (laboratory 2: GenID/AID Diagnostika; laboratory 3: Microbiology Laboratory, University of Zurich, Switzerland). Different assay lots were used in different laboratory settings. in first position on the left). d Table representing each HPV type and the average coloring strength of all 3 probe spots for each probe as a percentage. The HPV probes that are positive have their table cells highlighted in red. The table cells of negative HPV probes are colored blue.

\section{Results Analysis}

The diagnostic accuracy of HPV DNA Array, as well as analytical sensitivity and specificity, were calculated in comparison with the gold standard test MPG. Analysis was performed on 23 HPV types covered by both assays (HPV6, 11, 16, 18, 26, 31, 33, 35, $39,42,45,51,52,53,54,56,58,59,66,68,70,73$, and 82$)$. The sensitivity was calculated with the formula: number of true positives/ (number of true positives + number of false negatives); and the specificity was calculated with the formula: number of true negatives/(number of true negatives + number of false positives). The sensitivity, specificity, and agreement were evaluated using Cohen's kappa (k). The HPV detection was calculated irrespective of type, as well as for each specific HPV type. The $\mathrm{k}$ value was interpreted as follow [17]: poor $(<0.20)$, fair $(0.21-0.40)$, moderate (0.41-0.60), good (0.61-0.80), very good (0.81-1.00). The McNemar test was used with a $95 \%$ level of confidence to determine whether the difference between assays was significant. Pearson correlation was performed to assess the association between certain HPV types.

The agreement for HPV detection within the intra- and interlaboratory reproducibility detection was calculated irrespective of HPV type. Statistical analysis was performed with IBM SPSS Statistics for Windows (version 21.0, IBM Corp., Armonk, NY, USA) and MedCalc 15.8 (MedCalc Software, Ostend, Belgium). 
Table 1. HPV DNA Array HPV16, 18, 45, and GapDH probe sensitivity in cells per PCR reaction

\begin{tabular}{lcll}
\hline & $\begin{array}{l}\text { SiHa } \\
(\text { HPV16+) }\end{array}$ & $\begin{array}{l}\text { HeLa } \\
(\text { HPV18+) }\end{array}$ & $\begin{array}{l}\text { MS751 } \\
(\text { HPV45+) }\end{array}$ \\
\hline HPV type & 1 & 100 & 100 \\
Gap DH control & 100 & 100 & 100 \\
\hline
\end{tabular}

PCR reactions were tested in 2 independent determinations.

Table 2. Agreement between HPV DNA Array and MPG, stratified by MPG HPV results

\begin{tabular}{lrcc}
\hline & MPG & $\begin{array}{l}\text { HPV DNA } \\
\text { Array }\end{array}$ & $\%$ \\
\hline HPV detection & & & \\
MPG HPV- & 28 & 26 & 92.9 \\
MPG HPV+ & 244 & 225 & 92.2 \\
$\quad$ Single HPV+ & 184 & 167 & 90.8 \\
Multiple HPV+ & 60 & 58 & 96.7 \\
HR-HPV+ & 218 & 197 & 90.4 \\
LR-HPV+ & 48 & 39 & 81.3 \\
14 HR-HPV $+{ }^{1}$ & 184 & 168 & 91.8 \\
\hline
\end{tabular}

${ }^{1}$ HPV16, 18, 31, 33, 35, 39, 45, 51, 52, 56, 58, 59, 66, 68.

\section{Results}

Detection of HPV in Cervical Cancer Cell Lines and Probe Sensitivity

Cells from 7 cervical cancer cell lines (HeLa, SiHa, CaSki, CERV, MS-751, ME-180, and C33A) were resuspended in both PBS and in PreservCyte. The expected HPV type of each cell line was correctly identified after storage in both media (CaSki-HPV16, SiHa-HPV16, HeLa-HPV18, CERV-HPV45, MS-751-HPV45, ME-180HPV68, and C33A-HPV DNA negative, for which sample adequacy was controlled by positive GapDH).

The PCR and probe hybridization sensitivity of HPV16, 18, 45, and GapDH were tested with titration series of SiHa, HeLa, and MS751 cells in concentrations from $10^{4}$ cells per PCR reaction to $10^{-2}$ cells per PCR reaction (Table 1). In 2 independent determinations, the detection limit for HPV identification was 1 cell per PCR reaction for HPV 16 and $10^{2}$ cells per PCR reaction for HPV18 and 45. The detection limit for the GapDH control was $10^{2}$ cells per PCR reaction for all 3 cell lines. No difference between different passages of each cervical cancer cell line was observed. We also observed a high specificity of the probes investigated for these HPV genotypes represented by the cell lines as there was no crossreaction observed.

Analytical Sensitivity, Specificity, and Performance of HPV DNA Array as Compared to MPG as the Gold

\section{Standard}

The sample set comprised of 272 samples collected with known MPG results: 184 with single HPV infection (27 with LR-HPV and 157 with HR-HPV), 60 with multiple HPV infections, and $28 \mathrm{HPV}$ negative. All samples were tested with the HPV DNA Array. Nine samples demonstrated positive HPV types with a negative Gap control with HPV DNA Array. These samples were included in the analysis. No case of an HPV-negative sample with negative Gap control with HPV DNA Array was found.

Two hundred and nineteen samples showed concordant results, and in 54 samples discordant results were observed: either HPV DNA Array+/MPG-, HPV DNA Array-/MPG+, or both positive but not for same HPV type.

\section{Sample Retesting}

To avoid operational mistakes, the 54 discordant samples were retested with HPV DNA Array in order to potentially correct any technically introduced mistakes and get the most accurate results for the technical assay validation. Ten formerly concordant samples were also retested as controls. All 10 control samples had the same concordant result after retesting, proving general reliability of the retesting. We found that in $40 / 54$ samples that had discordant results, the retested results were still discordant to MPG. In 14/54 samples, however, the result changed and now matched MPG for at least 1 HPV type.

The 40 samples that were still discordant after HPV DNA Array retesting were also retested with MPG. Fourteen formerly concordant samples were included as a control, and these remained concordant upon retesting. We found that in 29/40 discordant samples the result stayed the same, hence a discordance was verified. In $11 / 40$ samples, however, the result changed upon retesting, and now matched the HPV DNA Array results.

In summary, out of the 54 initially discordant samples between HPV DNA Array and MPG after retesting, 14 became concordant by correcting the HPV DNA Array result and 11 samples became concordant by correcting the MPG result. In total, 25 became concordant, while 29 remained discordant between the 2 assays. These final re- 
Table 3. Analytical comparison in HPV detection between HPV DNA Array and MPG

\begin{tabular}{|c|c|c|c|c|c|c|}
\hline $\begin{array}{l}\text { HPV } \\
\text { genotyping }\end{array}$ & MPG & $\begin{array}{l}\text { HPV DNA } \\
\text { Array }\end{array}$ & Sensitivity, \% & $\kappa(95 \% \mathrm{CI})$ & Interpretation $^{1}$ & $\begin{array}{l}\text { McNemar } \\
p \text { value }\end{array}$ \\
\hline \multicolumn{7}{|l|}{ HR-HPV } \\
\hline HPV18 & 15 & 13 & 86.7 & $0.925(0.821$ to 1$)$ & Very good & 0.500 \\
\hline HPV26 & 4 & 3 & 75 & $0.194(-0.001$ to 0.389$)$ & Poor & 0.000 \\
\hline HPV31 & 16 & 15 & 93.8 & $0.656(0.491$ to 0.822$)$ & Good & 0.002 \\
\hline HPV35 & 14 & 14 & 100 & $0.929(0.832$ to 1$)$ & Very good & 0.500 \\
\hline HPV39 & 18 & 13 & 72.2 & $0.829(0.683$ to 0.975$)$ & Very good & 0.063 \\
\hline HPV45 & 15 & 15 & 100 & $0.903(0.795$ to 1$)$ & Very good & 0.250 \\
\hline HPV51 & 23 & 14 & 60.9 & $0.718(0.553$ to 0.883$)$ & Good & 0.021 \\
\hline HPV52 & 18 & 15 & 83.3 & $0.730(0.571$ to 0.89$)$ & Good & 0.344 \\
\hline HPV53 & 16 & 12 & 75 & $0.553(0.366$ to 0.741$)$ & Moderate & 0.049 \\
\hline HPV68 & 8 & 6 & 75 & $0.346(0.133$ to 0.559$)$ & Fair & 0.000 \\
\hline HPV73 & 10 & 6 & 60 & $0.743(0.501$ to 0.985$)$ & Good & 0.125 \\
\hline HPV82 & 12 & 8 & 66.7 & $0.753(0.544$ to 0.961$)$ & Good & 0.375 \\
\hline \multicolumn{7}{|l|}{ LR-HPV } \\
\hline HPV6 & 11 & 10 & 90.9 & $0.950(0.854$ to 1$)$ & Very good & 1.000 \\
\hline HPV11 & 2 & 1 & 50 & $0.496(-0.107$ to 1$)$ & Moderate & 1.000 \\
\hline HPV42 & 16 & 13 & 81.3 & $0.606(0.425$ to 0.787$)$ & Good & 0.035 \\
\hline HPV54 & 8 & 5 & 62.5 & $0.375(0.129$ to 0.621$)$ & Fair & 0.035 \\
\hline HPV70 & 12 & 6 & 50 & $0.657(0.401$ to 0.912$)$ & Good & 0.031 \\
\hline
\end{tabular}

Interpretation of $\kappa$ values: poor $(<0.20)$, fair $(0.21-0.40)$, moderate $(0.41-0.60)$, good $(0.61-0.80)$, very good $(0.81-1.00)$.

sults were used for the technical performance calculations of the HPV DNA Array assay.

Agreement between HPV DNA Array and MPG among Clinical Cervical Scrapings

After retesting of discrepant samples, the results of all samples were analyzed and are shown in Table 2. In the MPG HPV-negative samples, 26 samples were also negative with the HPV DNA Array $(26 / 28,92.9 \%)$. However, 2 were positive for HPV16 and 31, respectively, with the HPV DNA Array.

Among the MPG HPV-positive samples, HPV DNA Array was positive in $225 / 244$ samples (92.2\%). This group was stratified according to HPV single/multiple infection status. Agreement for non-type-specific HPV detection of $90.8 \%$ was observed in the MPG single infection group (167/184), and within the multiple infections group it was $96.7 \%$ (58/60). When stratifying the MPG HPV-positive samples according to HPV risk group, agreement was higher within the HR-HPV group (90.4\%,
197/218) than the LR-HPV group (81.3\%, 39/48). The HR-HPV agreement became greater when focusing on the 14 most important HR types (HPV16, 18, 31, 33, 35, $39,45,51,52,56,58,59,66,68)$, with $169 / 184(91.84 \%)$ detected. Including all samples (HPV positive and negative), the agreement for HPV-positivity detection (irrespective of type) was $92.3 \%$ by HPV DNA Array, with $\kappa=$ 0.671 (95\% CI 0.542-0.799), demonstrating good agreement between the assays, and with a specificity of $92.86 \%$.

Type-Specific Agreement between HPV DNA Array and MPG among Clinical Cervical Scrapings

The sensitivity for detection of individual HPV types is presented in Table 3. It varied from $28.6 \%$ for HPV56 to $100 \%$ for HPV $33,35,45$, and 58 , with an average of $73.6 \%$ over all genotypes. HPV DNA Array had a very high specificity for each HPV type with an average value of $98.0 \%$, varying from $92.2 \%$ for HPV26 to $100 \%$ for HPV6, 18, 39, 66, 70, and 73. The $\kappa$ values varied from 0.194 for HPV26 to 0.958 for HPV33. An average $\kappa$ of 0.67 
Table 4. Distribution of HPV genotypes in single and multiple infections among discordant HPV DNA Arraynegative/MPG-positive results

\begin{tabular}{|c|c|c|c|c|c|}
\hline & \multicolumn{2}{|c|}{ MPG single infection } & \multicolumn{3}{|c|}{ MPG multiple infections } \\
\hline & concordant & discordant & concordant & discordant & $\begin{array}{l}\text { other HPV types detected } \\
\text { in multiple infection }{ }^{1}\end{array}$ \\
\hline HPV16 & 22 & 1 & 24 & 10 & $10 / 10$ \\
\hline HPV 18 & 9 & 1 & 4 & 1 & $1 / 1$ \\
\hline HPV26 & 3 & 0 & 0 & 1 & $0 / 1$ \\
\hline HPV31 & 10 & 1 & 6 & 0 & $0 / 0$ \\
\hline HPV39 & 7 & 0 & 6 & 5 & $5 / 5$ \\
\hline HPV51 & 8 & 0 & 6 & 9 & $9 / 9$ \\
\hline HPV52 & 9 & 1 & 6 & 2 & $2 / 2$ \\
\hline HPV53 & 8 & 1 & 4 & 3 & $2 / 3$ \\
\hline HPV56 & 2 & 6 & 4 & 9 & $7 / 9$ \\
\hline HPV59 & 3 & 2 & 3 & 3 & $2 / 3$ \\
\hline HPV66 & 3 & 2 & 2 & 4 & $3 / 4$ \\
\hline HPV68 & 6 & 0 & 0 & 2 & $2 / 2$ \\
\hline HPV73 & 5 & 2 & 1 & 2 & $2 / 2$ \\
\hline HPV82 & 7 & 1 & 1 & 3 & $3 / 3$ \\
\hline HPV6 & 9 & 0 & 1 & 1 & $1 / 1$ \\
\hline HPV 11 & 0 & 1 & 1 & 0 & $0 / 0$ \\
\hline HPV42 & 10 & 0 & 3 & 3 & $3 / 3$ \\
\hline HPV 54 & 2 & 0 & 3 & 3 & $3 / 3$ \\
\hline HPV70 & 3 & 2 & 3 & 4 & $4 / 4$ \\
\hline
\end{tabular}

The results included no missed samples for HPV33, 35, 45.

${ }^{1}$ Number of samples in which HPV DNA Array matched MPG for $\geq 1$ HPV genotype, but was negative for the respective HPV type.

demonstrated a good agreement between the assays by HPV type. We observed a very good agreement for HPV 16 and 18, with a high $\kappa$ of 0.836 and 0.925 , and sensitivity of 80.7 and $86.7 \%$, respectively. The agreement among HR-HPV types by $\kappa$ value was considered to be very good/good $(\kappa>0.6)$ for HPV16, 18, 31, 33, 35, 39, 45, $51,52,58,66,73$, and 82 , although the difference for detection in both assays was deemed statistically significant by McNemar test for HPV31, 51, and 66.

Pearson correlation analysis discovered a cross-reactivity between HPV26 and HPV35 probes. A higher number of HPV26 HPV DNA Array-positive samples $(n=21)$ was observed, which were negative by MPG, explaining the low $\kappa$ agreement and specificity for this rare genotype.

Verification of HPV Genotype Status in HPV DNA

Array Negative Samples in Single and Multiple

Infections Compared with MPG

To further understand the discrepancy in HPV-type detection, the samples in which a respective HPV type was HPV DNA Array-/MPG+ were stratified by dividing into
MPG single or multiple infections (Table 4). In some samples 2 or more HPV types were HPV DNA Array-/MPG+.

In total, it was found that in 22/80 (26\%) samples a respective HPV type was missed by HPV DNA Array, while it was present in MPG as a single HPV genotype infection. In contrast, in 63/80 (74\%) cases a genotype was missed by HPV DNA Array when it was present in MPG in a multiple genotype infection. It was observed that in 57/63 (90\%) samples with multiple infections other types present in the infection were detected instead by HPV DNA Array.

This corresponds with our finding from the above section (Agreement between HPV DNA Array and MPG among Clinical Cervical Scrapings) that the agreement for general HPV detection (irrespective of type) between the assays was higher in multiple $(96.7 \%, 58 / 60)$ versus single $(90.8 \%, 167 / 184)$ infections.

\section{Intra- and Inter-Laboratory Reproducibility}

Within intra-assay/intra-laboratory experiments, agreement for HPV detection was $100 \%(22 / 22, \kappa=1)$ between all 4 sets in one plate run. Agreement for HPV 
detection between different performers within inter-assay/intra-laboratory reproducibility was $100 \%(22 / 22, \kappa=$ 1 ), and within inter-laboratory reproducibility was $100 \%$ $(22 / 22, \kappa=1)$ for the second and $90.9 \%(20 / 22, \kappa=0.69)$ for the third laboratory, where $2 \mathrm{HPV}$-positive samples were marked HPV negative.

\section{Discussion}

This is the first report on analytical performance of the HPV DNA Array, an E1-based multiplexed PCR assay for full HPV genotyping. HPV DNA Array has been demonstrated to be a simple and robust assay, with a short 4-h protocol, with a hands-on time of approximately $2 \mathrm{~h}$, a reverse hybridization step, and an ELISA-like staining for assay development. The automated ELISPOT reader AiDot evaluates the full 96-well plate in approximately $3 \mathrm{~min}$, permitting high throughput and time efficacy. Automated plate readout and analysis by AiDot software avoids subjective variability. The data can be exported in various formats (e.g., Microsoft Word), as well as stored for documentation and re-evaluation.

Experiments performed on different cervical cancer cell lines established the high sensitivity for detection from cellular material. Importantly, HPV DNA Array proved it can be run from native PBS non-fixed material or PreservCyte samples that are used routinely for cervical sampling. In addition, a high sensitivity for specific probes was observed, such as 1 cell/PCR for HPV16 and 100 cells/PCR reaction for HPV18 and 45.

Intra- and inter-laboratory reproducibility experiments demonstrated highly reproducible agreement for general HPV detection $(100 \%, \kappa=1)$ within intra- and inter-laboratory experiments, except for lower agreement of laboratory $3(20 / 22,90 \%, \kappa=0.69)$ within inter-laboratory reproducibility. This could be due to restricted experience of the performer only recently acquainted with the assay protocol, contrary to the longer experience of the first 2 laboratories.

Reproducibility experiments highlighted the reliability and reproducibility of the assay; however, when retesting the discordant samples with HPV DNA Array, in a number of samples the HPV results changed (22/54 retested samples). Similarly, the results changed with MPG after retesting of discordant samples (11/40). This peculiar phenomenon could be caused by pipetting errors or contamination, all of which could accompany the PCR diagnostics and hybridization, or be due to low viremic samples where by chance the viral template is captured or not in the PCR reaction. In an effort to get the more accurate HPV results, especially for validation purposes, the retesting of discordant samples was performed and included in the analysis. Such retesting would not be feasible in a screening setting or as part of routine diagnostics.

Comprehensive analysis on HPV detection in clinical samples against MPG demonstrated good agreement $(\kappa=$ $0.671,95 \%$ CI $0.542-0.799$ ) for HPV positivity detection. High agreement of $>90 \%$ was documented when stratifying for single/multiple infection status and type-specific carcinogenic risk, with slightly lower agreement among LR-HPV types of $88 \%$. It is worth mentioning that while detection and evaluation of LR-HPV types is important for epidemiological purposes, it is not recommended for cervical cancer screening.

Very good agreement for the most frequent cancercausing types HPV 16 and 18 was found with a $\kappa$ of 0.836 (95\% CI 0.753-0.919) and 0.925 (95\% CI 0.821-1), respectively; which is important, as HPV16 and 18 account for more than $70 \%$ of cervical cancers [5]. Agreement for HPV $31,33,35,52$, and 58, which together with HPV 16 and 18 account for $89 \%$ of cervical cancers [5], was found to be good to very good with $\kappa$ values higher than 0.6 . Poor/fair agreement $(\kappa<0.4)$ was found for HPV26, 56, 68 among HR-HPV types. Pearson correlation analysis discovered a cross-reactivity between HPV 26 and HPV 35 probes, as a higher number of samples HPV26-positive with HPV DNA Array but negative with MPG (21 samples) were observed, explaining the low $\kappa$ agreement and specificity for this rare genotype. It was noted for future genotyping analysis that such cross-reactions may occur. HPV56 and 68 are the 10th and 12th ranking cancercausing types in the world [5].

To further investigate the reason for missing genotypes by HPV DNA Array that resulted in lower agreement to the gold standard assay MPG, a stratification of the samples in relation to single versus multiple infections was performed. It was observed that when an HPV type was missed by HPV DNA Array, it was more frequently in MPG multiple infections (22\% missed in single vs. $74 \%$ missed in multiple infections). If a certain HPV type was missed by HPV DNA Array in MPG-detected multiple infections, it was observed that in $90 \%$ of cases at least one other HPV type was detected by DNA Array.

Evidently, as found within the LabNet Proficiency studies [18], for many assays on the market HPV genotypes are more difficult to detect when present in multiple infections. Similarly, in our study, the sensitivity for detection of a certain genotype was lower when present in multiple infections. However, importantly, overall sensi- 
tivity for the detection of multiple infections, that is $>1$ genotype, was found to be high for HPV DNA Array, representing $96.6 \%(58 / 60)$ of respective samples. As multiple infections have a higher risk for developing into dysplasia [19-21], it is clinically important not to miss those.

Furthermore, in the LabNet Proficiency study, Eklund et al. [18] reported that the sensitivity for detection of different HPV genotypes among many assays varied between 41 and $97 \%$, which is similar to results reported within this study. Eklund et al. [18] found that the investigated assays tended to be more sensitive in detection of HPV16, 11, and 18 due to their epidemiological and clinical significance, however they were less sensitive than HPV31, 59, and 39, for example.

It must be considered that MPG has a very high analytical sensitivity $[14,15]$, which is of advantage for epidemiology, but may be a disadvantage for achieving an adequate level of clinical sensitivity. The analytical differences in our study could possibly be due to differences in assay design and the HPV gene targeted (HPV DNA Array-E1, MPG-L1). The study sample panel we used was selected to contain different HPV genotypes, and is not representative of a screening population, and no data on patient age or histology status were available.

Current guidelines for clinical validation of HPV assays recommended by Meijer et al. [22] were not followed within this study, as we aimed to describe HPV DNA Array and evaluate its analytical performance. Therefore, samples of cervical cancer cell lines and preselected cervical scrapings were used, and not samples from a screening population, as required by Meijer et al. [22]. However, the main intent of HPV testing should be the detection of clinically relevant cases. In an effort to evaluate the clinical sensitivity for high-grade lesions and cervical cancer, an additional study was organized revealing high sensitivity of HPV DNA Array for CIN2+ lesion detection [Pesic et al., accepted] and is reported elsewhere.

\section{Conclusion}

HPV DNA Array demonstrated a good analytical performance for HPV detection irrespective of type. Most importantly, it was concordant with MPG, with high sensitivity and agreement for HPV 16 and 18. HPV DNA Array is a reliable and sensitive PCR-based assay, with a simple workflow for individual genotype detection with the possibility to develop automatization. It can be performed as a high-throughput assay capable of testing up to 96 samples in one run. With an automated readout within 3

min per plate it is a full genotyping assay and should be investigated for applicability for epidemiology purposes or mass screening.

\section{Acknowledgements}

We appreciate the contribution of Ms. D. Schiller. We thank Erasmus Mundus Sigma Scholarship program, Serbian "Dositeja" Scholarship program, and Berliner Krebsgesellschaft e.V. for financial support to A.P.

\section{Statement of Ethics}

The study was conducted ethically in accordance with the World Medical Association Declaration of Helsinki (https://www. wma.net/policies-post/wma-declaration-of-helsinki-ethical-principles-for-medical-research-involving-human-subjects/). Patients consented to the use of residual diagnostic material for research (IRB Charite-Universitätsmedizin Berlin, No. EA1/168/13).

\section{Disclosure Statement}

A.P. received travel grants from AID/GeinID. M.H. and R.P. are employed at AID/GenID. AID/GenID provided the necessary kits free of charge. They had no role in study design, data collection, or analysis.

\section{Funding Sources}

There was no formal funding for this research.

\section{Author Contributions}

A.P. carried out the experiments and prepared the manuscript; A.K. and C.S. carried out the experiments; M.H. and R.P. carried out the control experiments; A.M.K. provided the original ideas and experimental structure, supervision, and supported the experiments and manuscript writing.

References

Intervirology 2019;62:124-133

DOI: $10.1159 / 000502207$

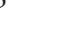

1 Ho GY, Bierman R, Beardsley L, Chang CJ, Burk RD. Natural history of cervicovaginal papillomavirus infection in young women. $\mathrm{N}$ Engl J Med. 1998 Feb;338(7):423-8.

2 de Villiers EM, Fauquet C, Broker TR, Bernard HU, zur Hausen H. Classification of papillomaviruses. Virology. 2004 Jun;324(1): 17-27.

3 Garland SM, Steben M, Sings HL, James M, Lu S, Railkar R, et al. Natural history of genital warts: analysis of the placebo arm of 2 randomized phase III trials of a quadrivalent human papillomavirus (types 6,11,16, and 18) vaccine. J Infect Dis. 2009 Mar;199(6):805-14. 
4 Bosch FX, Lorincz A, Muñoz N, Meijer CJ, Shah KV. The causal relation between human papillomavirus and cervical cancer. J Clin Pathol. 2002 Apr;55(4):244-65.

5 Clifford G, Franceschi S, Diaz M, Munoz N, Villa LL. Chapter 3: HPV type-distribution in women with and without cervical neoplastic diseases. Vaccine. 2006 Aug;24 Suppl 3:2634.

6 Wright TC Jr. Cervical cancer screening in the 21st century: is it time to retire the PAP smear? Clin Obstet Gynecol. 2007 Jun;50(2): $313-23$.

7 Cuzick J, Arbyn M, Sankaranarayanan R, Tsu V, Ronco G, Mayrand MH, et al. Overview of human papillomavirus-based and other novel options for cervical cancer screening in developed and developing countries. Vaccine. 2008 Aug;26 Suppl 10:K29-41.

8 Ronco G, Dillner J, Elfström KM, Tunesi S, Snijders PJ, Arbyn M, et al.; International HPV screening working group. Efficacy of $\mathrm{HPV}$-based screening for prevention of invasive cervical cancer: follow-up of four European randomised controlled trials. Lancet. 2014 Feb;383(9916):524-32.

9 Elfstrom KM, Smelov V, Johansson AL, Eklund C, Naucler P, Arnheim-Dahlstrom L, et al. Long term duration of protective effect for HPV negative women: follow-up of primary HPV screening randomised controlled trial. BMJ. 2014 Jan;348:g130.

10 Bulkmans, N.W.J., L. Rozendaal, F.J. Voorhorst, P.J.F. Snijders, and C.J.L.M. Meijer, Long-term protective effect of high-risk hu- man papillomavirus testing in populationbased cervical screening. Br J Cancer. 2005;92: 1800.

11 Trimble CL, Piantadosi S, Gravitt P, Ronnett B, Pizer E, Elko A, et al. Spontaneous regression of high-grade cervical dysplasia: effects of human papillomavirus type and HLA phenotype. Clin Cancer Res. 2005 Jul;11(13): 4717-23.

12 Elfgren K, Elfström KM, Naucler P, ArnheimDahlström L, Dillner J. Management of women with human papillomavirus persistence: long-term follow-up of a randomized clinical trial. Am J Obstet Gynecol. 2017 Mar;216(3): 264.e1-264.e7.

13 Trottier H, Mahmud S, Costa MC, Sobrinho JP, Duarte-Franco E, Rohan TE, et al. Human papillomavirus infections with multiple types and risk of cervical neoplasia. Cancer Epidemiol Biomarkers Prev. 2006 Jul;15(7):127480.

14 Schmitt M, Dondog B, Waterboer T, Pawlita $\mathrm{M}$. Homogeneous amplification of genital human alpha papillomaviruses by PCR using novel broad-spectrum GP5+ and GP6+ primers. J Clin Microbiol. 2008 Mar;46(3): 1050-9.

15 Schmitt M, Bravo IG, Snijders PJ, Gissmann L, Pawlita M, Waterboer T. Bead-based multiplex genotyping of human papillomaviruses. J Clin Microbiol. 2006 Feb;44(2): 504-12.

16 Geraets DT, Cuschieri K, de Koning MN, van Doorn LJ, Snijders PJ, Meijer CJ, et al. Clinical evaluation of a GP5+/6+-based luminex assay having full high-risk human papillomavirus genotyping capability and an internal control. J Clin Microbiol. 2014 Nov;52(11):39964002.

17 Altman DG. Practical statistics for medical research. Boca Raton: Chapman and Hall/CRC; 2006.

18 Eklund C, Forslund O, Wallin KL, Dillner J. Global improvement in genotyping of human papillomavirus DNA: the 2011 HPV LabNet International Proficiency Study. J Clin Microbiol. 2014 Feb;52(2):449-59.

19 Pista A, Oliveira A, Verdasca N, Ribeiro F. Single and multiple human papillomavirus infections in cervical abnormalities in Portuguese women. Clin Microbiol Infect. 2011 Jun;17(6):941-6.

20 Bachtiary B, Obermair A, Dreier B, Birner P, Breitenecker G, Knocke TH, et al. Impact of multiple HPV infection on response to treatment and survival in patients receiving radical radiotherapy for cervical cancer. Int J Cancer. 2002 Nov; 102(3):237-43.

21 Herrero R, Castle PE, Schiffman M, Bratti MC, Hildesheim A, Morales J, et al. Epidemiologic profile of type-specific human papillomavirus infection and cervical neoplasia in Guanacaste, Costa Rica. J Infect Dis. 2005 Jun; 191(11):1796-807.

22 Meijer CJ, Berkhof J, Castle PE, Hesselink AT, Franco EL, Ronco G, et al. Guidelines for human papillomavirus DNA test requirements for primary cervical cancer screening in women 30 years and older. Int J Cancer. 2009 Feb; 124(3):516-20. 